\title{
Regência e análise de uma sequência de aulas de química: contribuições para a formação inicial docente reflexiva
}

\author{
Teaching and analysis of a chemistry didactic sequence: \\ contributions for reflective pre-service teacher training
}

Lívia Maria Ribeiro Rosa ${ }^{1}$. Rita de Cássia Suart ${ }^{1}$. Maria Eunice Ribeiro Marcondes ${ }^{2}$

\begin{abstract}
Resumo: As propostas de ensino têm apontado para a necessidade de os professores atuarem como mediadores da construção do conhecimento pelos estudantes. Assim, é preciso inserir os futuros professores em contextos nos quais metodologias e estratégias de ensino e aprendizagem possam ser criticamente refletidas, e, o Processo de Reflexão Orientada é uma proposta para que os licenciandos experimentem momentos de reflexão durante a elaboração e o desenvolvimento de ações relacionadas à futura prática docente. Neste sentido, este trabalho investigou as contribuições do processo de reflexão orientada na formação inicial de uma licencianda de Química, durante o desenvolvimento e a análise de uma sequência de aulas elaborada por ela, considerando a abordagem investigativa e para a promoção da alfabetização científica. Os resultados mostram que a licencianda conseguiu desenvolver sua prática considerando alguns aspectos investigativos, o que contribuiu para uma formação mais reflexiva.
\end{abstract}

Palavras-chave: Ensino de química. Alfabetização científica. Ensino por investigação. Formação inicial de professores.

\begin{abstract}
Teaching proposals have pointed out the need for teachers mediate knowledge development by students. Therefore, future teachers must experience contexts, methodologies and teaching and learning strategies that can be critically reflected upon. The Oriented Reflection Process is a proposal for pre service teachers to reflect about their experiences during the design and development stages related to future teaching practice. In this sense, this study investigated the contributions of oriented reflection processes by a pre-service chemistry teacher during the implementation and analysis of a class sequence proposed by herself, within the investigative and scientific literacy approach. The results show that the pre-service teacher developed their practice by considering some investigative aspects, which contributed to a more reflective teacher practice.
\end{abstract}

Keywords: Scientific literacy. Chemistry teaching. Investigative teaching. Pre-service teacher.

\footnotetext{
${ }^{1}$ Universidade Federal de Lavras (UFLA), Departamento de Educação, Lavras, MG, Brasil. E-mail: <mendesufla@gmail.com>.

${ }^{2}$ Universidade de São Paulo (USP), Instituto de Química, São Paulo, SP, Brasil.
} 


\section{Introdução}

As atuais propostas de ensino e de aprendizagem de ciências têm indicado a proposição de metodologias que possibilitem ao aluno desenvolver e construir seus conhecimentos e habilidades de ordens superiores (MORTIMER, 2010). Investir em atividades nas quais os alunos irão pensar e avaliar condições, elaborando hipóteses e soluções para um problema proposto, pode contribuir para sua formação cidadã crítica, e o ensino por investigação é uma das estratégias pela qual se pode valorizar o desenvolvimento de habilidades relativas ao processo da alfabetização científica (SASSERON; CARVALHO, 2008).

Torna-se então evidente a importância de se investir nos cursos de formação de professores, a fim de proporcionar aos licenciandos vivências que possibilitem o desenvolvimento mais efetivo de sua futura prática docente. Porém, muitos cursos de formação de professores ainda oferecem poucos momentos que possibilitam aos licenciandos vivenciar uma formação mais completa, já que poucos são os espaços para que eles possam relacionar as teorias vistas na universidade com o cenário educacional. Assim, muitos professores, ao concluírem o curso de licenciatura, se deparam com situações em que não sabem, ou pouco sabem, sobre a carreira docente.

Nesse sentido, é importante destacar a necessidade de inserir os licenciandos em contextos nos quais metodologias e estratégias de ensino e aprendizagem possam ser criticamente refletidas, e os grupos de reflexão orientada podem contribuir para uma formação nessa perspectiva (ABELL; BRYAN, 1997; ALVES; LIMA; MARCONDES, 2012). A participação nesses grupos pode auxiliar na construção da identidade profissional do futuro professor, bem como, na significação e ressignificação de seu papel na sociedade.

Partindo dessas ideias, o presente trabalho investigou as contribuições do processo de reflexão orientada na formação inicial docente de uma licencianda de Química, durante o desenvolvimento e análise de uma sequência de aulas elaborada por ela, considerando a abordagem investigativa e a promoção da alfabetização científica no ensino médio.

\section{Referencial teórico}

\section{A formação reflexiva de professores}

Muitos cursos de formação inicial de professores ainda têm contemplado poucas oportunidades para que os futuros professores possam relacionar os conhecimentos apreendidos durante a formação inicial com situações da prática docente, de modo a contribuir para uma formação mais reflexiva (GATTI, 2011; PREDEBON; PINO, 2009; SILVA; SCHNETZLER, 2008; VILLANI; FRANZONI; VALADARES, 2008). Em muitos casos, os cursos contemplam uma vasta carga horária para as disciplinas específicas e poucas atividades referentes à formação pedagógica dos futuros professores (GATTI, 2011; SILVA; SCHNETZLER, 2008).

Gatti (2011, p. 218) destaca que nos currículos dos cursos de formação inicial:

[...] é reduzido o número de disciplinas teóricas da área de Educação (Didática, Psicologia da Educação ou do Desenvolvimento, Filosofia da Educação etc.) e que, mesmo as disciplinas aplicadas, têm espaço pequeno 
Regência e análise de uma sequência de aulas de química: ...

nas matrizes, sendo que estas, na verdade, são mais teóricas que práticas, onde deveria haver equilíbrio entre esses dois eixos. Com essas características apontadas, com vasto rol de disciplinas e com a ausência de um eixo formativo para a docência claro, presume-se a pulverização na formação dos licenciados, o que indica frágil preparação para o exercício do magistério na educação básica.

Em pesquisa realizada por Silva e Oliveira (2009) com formandos do curso de Química de uma universidade paulista, os autores evidenciaram que os licenciandos destacaram como um dos pontos positivos do curso, a excelência na formação específica nas disciplinas de Química, seja para atuação no mercado de trabalho como químico, ou como professor. No entanto, os licenciandos destacaram a "[...] desarticulação entre os conteúdos específicos e pedagógicos" (SILVA; OLIVEIRA, 2009, p. 55) demonstrando, assim, a falta de interação nas diversas disciplinas e atividades do curso de licenciatura, o que, como ressaltam os autores, é um dos fatores que "[...] favorecem a má-formação dos professores de Química" (SILVA; OLIVEIRA, 2009, p. 55). Com relação às atividades diretamente relacionadas ao cenário escolar, os licenciandos ressaltam a pouca vivência de práticas escolares.

Cabe, nesse momento, ressaltar as palavras de Silva e Schnetzler (2008), as quais consideram que é na universidade a chance que o professor em formação tem para relacionar os conhecimentos teóricos à prática docente. As autoras consideram os estágios supervisionados como experiências que possibilitam a construção dessa relação para a formação do professor.

Portanto, o estágio supervisionado e as disciplinas de práticas pedagógicas deveriam colocar o licenciando em uma nova situação: a de questionar e refletir o processo de ensino e aprendizagem e a prática docente. No entanto, muitas vezes, as 400 horas de estágio supervisionado são destinadas a atividades de observação. Isso pode acontecer pelo fato de muitos professores orientadores de estágio nas universidades não serem habilitados para atuarem na formação inicial de professores.

Segundo Maldaner (2000, p. 47):

As críticas são feitas, principalmente, pelos alunos desses cursos quando começam a frequentar disciplinas de formação pedagógica ou nos encontros em que refletem sobre sua formação. Os estudantes criticam, com razão, desde a falta de didática da maioria dos professores da Graduação, passando pela dicotomia das aulas práticas e teóricas, até a falta de transparência dos conteúdos de Química para o ensino secundário e elementar. Podemos afirmar que há um despreparo pedagógico dos professores universitários e isso afeta a formação em Química de maneira geral, não só licenciandos.

Kasseboehmer e Ferreira (2008, p. 695) ressaltam a relevância de as atividades de estágio serem mediadas pela reflexão, destacando que “[...] todos os formadores do curso de licenciatura tornam-se responsáveis por propiciar momentos de discussão que contribuam para a formação do licenciando".

Assim, acreditamos que no processo de formação inicial, o licenciando precisa começar a assumir uma nova postura questionadora e reflexiva de sua prática, compreendendo que não 
basta apenas dominar os conteúdos específicos ou as teorias de ensino; mas sim, inter-relacionar esses dois campos de conhecimento. Considerar o pensamento do futuro professor durante o processo formativo significa conceber que ele não é um técnico que aplica metodologias prontas, mas alguém que constrói e processa as informações, toma decisões, gera rotinas e conhecimentos práticos, e principalmente, possui crenças sobre sua atividade profissional (MELLADO JIMÉNEZ, 1996).

Para Alarcão (2011, p. 44)

A noção de professor reflexivo baseia-se na consciência da capacidade de pensamento e reflexão que caracteriza o ser humano como criativo e não como mero reprodutor de ideias e práticas que lhe são exteriores. É central, nesta conceptualização, a noção do profissional como uma pessoa que, nas situações profissionais, tantas vezes certas e imprevistas, atua de forma inteligente e flexível, situada e reativa.

Silva e Duarte (2002) indicam a importância de o professor desenvolver a habilidade de refletir sobre suas concepções e ações pedagógicas, para que possa compreender e justificar suas ações docentes. Freitas e Villani (2002, p. 216) também destacam a relevância da formação crítica e reflexiva dos profissionais da educação ao assumirem que: “[...] o saber sobre o ensino deixa de ser visto pela lógica da racionalidade técnica e incorpora a dimensão do conhecimento construído e assumido responsavelmente a partir de uma prática crítico-reflexiva". Assim, a reflexão dos futuros professores sobre suas ações e concepções se torna de extrema relevância para o desenvolvimento de atividades de ensino mais adequadas, e um modo de alcançar essa formação, voltada para a reflexão crítica da prática docente, pode ocorrer por meio do Processo de Reflexão Orientada (PRO).

O PRO pretende, por meio de um processo mediado por um investigador (mediador/ tutor), que o professor, ou futuro professor, reflita sobre aspectos relacionados à suas concepções de ensino e aprendizagem. Assim, baseado no pressuposto que os licenciandos têm suas próprias ideias, crenças e valores, a reflexão orientada (RO) se apoia no processo de reavaliação e reelaboração dessas ideias, e é caracterizada por favorecer aos professores, ambientes e contextos para descreverem e refletirem sobre essas ideias, e, com o auxílio do mediador/tutor, oferecer meios para ajudá-los a clarificar, confrontar e, às vezes, mudar suas teorias pessoais. Após a elaboração de materiais, leitura de artigos e regência de aula, por exemplo, realiza-se uma reflexão acerca dos acontecimentos das mesmas, sobre os comportamentos verbais e interativos à luz de suas concepções, epistemológicas e didáticas (ABELL; BRYAN, 1997).

Os encontros reflexivos podem ocorrer entre o mediador e um grupo de licenciandos (reflexão em grupo), ou entre o mediador e apenas um dos licenciandos (reflexão individual). Os encontros em grupos são relevantes para que os integrantes possam se socializar, confrontar e compartilhar as suas ideias e experiências vivenciadas. Esses encontros proporcionam momentos para que discussões teóricas e práticas fundamentem e orientem as ações dos licenciandos, de forma a explicitarem suas impressões sobre a prática do colega, contribuindo para a multiplicidade de ideias. Já os encontros individuais são relevantes para individualizar o processo de cada licenciando envolvido (COPELLO LEVY; SANMARTI PUIG, 2001). 
Regência e análise de uma sequência de aulas de química: ...

Assim, é essencial em um processo reflexivo um apoio para que o professor, ou futuro professor, perceba a sua formação como uma experiência educativa válida para si mesmo. Por isso a importância da orientação, ou mediação, de um professor com maior experiência. Para Alarcão (2011), a supervisão, ou no caso deste trabalho, a orientação, se define como um processo onde um professor mais experiente e mais informado, em princípio, orienta um outro professor, ou futuro professor, no seu desenvolvimento humano e profissional. O supervisor, ou mediador, é fundamentalmente um gestor e animador de situações e recursos intra e interpessoais com vista à formação, para desenvolver uma interação entre o pensamento e a ação, com o objetivo de dar sentido ao vivido e ao conhecido, isto é, de o professor em formação inicial compreender melhor para melhor agir.

Portanto, o professor deveria ser instigado a se tornar mais reflexivo desde a sua formação inicial, pois a reflexão e discussão oferecidas aos licenciandos podem possibilitar a eles se posicionarem criticamente em relação às suas futuras atividades docentes, desenvolvendo as suas consciências de que ser professor é assumir uma postura pedagógica de investigação, e não de mero repetidor de conhecimentos, contribuindo para que ele se torne um profissional mais autônomo (ALARCÃO, 2011; MELLADO JIMENEZ, 1996).

\section{Alfabetização científica e ensino por investigação}

O ensino de ciências ainda tem enfatizado o desenvolvimento conceitual em detrimento a relação dos conteúdos com aspectos associados à sociedade, ambiente e tecnologia (MORTIMER, 2010). Em contrapartida, as atuais propostas de ensino e aprendizagem, bem como diversos pesquisadores da área, têm argumento sobre a importância de prover ações e atividades que auxiliem os estudantes a compreenderem as ciências e seus conceitos, de modo que eles possam aplicar e utilizar as ideias científicas para interpretar e explicar os fenômenos de seu cotidiano (CACHAPUZ et al., 2005; MORTIMER, 2010).

Segundo Chassot (2003), ensinar ciências é uma maneira de possibilitar aos estudantes se transformarem em indivíduos mais críticos, o que pode levá-los a se tornarem agentes de transformação, atuando de maneira mais efetiva sobre a realidade que vivenciam. A fim de proporcionar uma melhor formação cidadã, é necessário oferecer aos indivíduos, habilidades relacionadas ao processo de alfabetização científica, de forma a proporcionar uma melhor compreensão e uma atuação mais crítica e reflexiva no desenvolvimento da sociedade como um todo. A alfabetização científica se faz importante, pois há a necessidade de se ter um mínimo de conhecimentos para, por exemplo, debater sobre assuntos relacionados a política, sociedade, tecnologias, entre outros (CACHAPUZ et al., 2005; CHASSOT, 2003). Assim, pode-se dizer que uma pessoa alfabetizada cientificamente é aquela que, através de um mínimo de conhecimentos, consegue compreender e explicar, criticamente, fatos relacionados ao seu cotidiano, por meio de habilidades também relacionadas à ética e à moral.

Desta forma, é importante que sejam utilizadas estratégias que possibilitem aos estudantes participarem ativamente do processo de aprendizagem (SUART; MARCONDES, 2009). Pode-se então destacar que cabe ao professor desenvolver propostas de modo a englobar atividades que privilegiem a solução de problemas, levando o aluno a investigar, refletir, elaborar hipóteses e propor possíveis conclusões para esse problema. As propostas de ensino 
por investigação consideram a participação dos alunos e do professor durante o processo de ensino e aprendizagem. Nessa perspectiva, o professor deve propor meios que possam estimular a aprendizagem dos estudantes por meio da relação entre os conceitos escolares ao contexto e cotidiano dos alunos (BIANCHINI, 2011; CACHAPUZ et al., 2005).

Por meio de uma situação problema, em um ensino por investigação, o aluno pode desenvolver habilidades como argumentação, proposição de hipóteses e justificativas a partir das ideias envolvidas, permitindo-os solucionar o problema levantado, desenvolvendo suas ideias e interpretando as informações e conceitos (BIANCHINI, 2011; CARVALHO, 2006; SILVA, 2011).

No entanto, muitos cursos de formação de professores parecem não atender a tais perspectivas. É indicado que o licenciando tenha acesso a novas metodologias de ensino e de aprendizagem, para que possa refletir criticamente sobre qual a melhor abordagem a ser utilizada em cada sala de aula, de forma a desenvolver nos estudantes, habilidades cognitivas e argumentativas, relacionadas à alfabetização científica.

\section{Metodologia}

Este trabalho se desenvolveu a partir de um processo de reflexão orientada (PRO) como uma atividade extracurricular ${ }^{3}$, do curso de Licenciatura em Química de uma universidade mineira, processo que se desenvolveu por meio de um grupo de reflexão orientada (GRO). O grupo era constituído de cinco licenciandos, uma professora do ensino médio e uma professora do referido curso de graduação, doutoranda em Ensino de Ciências ${ }^{4}$, a qual atuou como mediadora do grupo. É importante destacar que todos os licenciandos participaram voluntariamente das ações propostas e desenvolvidas pelo grupo, em um período de aproximadamente um ano e meio. Ainda, os cinco licenciandos já haviam concluído as disciplinas relacionadas à formação docente e estágio supervisionado. Desta forma, por se tratar de uma proposta extracurricular, destacam-se como importantes condicionantes para o desenvolvimento do PRO, a dedicação dos licenciandos durante o processo, sua preocupação com a formação docente, bem como, o interesse dos futuros professores em elaborar suas monografias de curso por meio das ações realizadas no PRO.

Esse processo realizou-se por meio de encontros em grupo e individuais. Nos encontros individuais, com duração de aproximadamente uma hora, cada licenciando se reunia com a mediadora do grupo, a fim de discutir, refletir e compartilhar sentimentos e ideias sobre aspectos diretamente relacionados ao estudo e planejamento de uma sequência de aulas a ser elaborada e desenvolvida em sala de aula. Os encontros em grupo aconteceram com a presença de todos licenciandos, a professora regente da escola de educação básica e a mediadora. Esses encontros

\footnotetext{
${ }^{3}$ A pesquisa ocorreu em período extracurricular por se tratar de uma proposta para pesquisa de doutorado de uma das pesquisadoras, a qual atuava como professora assistente no curso de licenciatura, mas encontrava-se afastada de suas ações docentes no período da pesquisa.

${ }^{4}$ Todos os dados utilizados nesse trabalho referem-se à pesquisa de doutorado, em andamento, de uma das autoras. Projeto registrado: CAAE 14508013.8.0000.5148.
} 
tinham duração de aproximadamente duas horas. É importante destacar que todos os encontros reflexivos, individuais e em grupo, foram gravados em áudio e vídeo, e posteriormente transcritos, de forma a contribuir para uma maior compreensão sobre o processo reflexivo realizado.

Com base na perspectiva da reflexão orientada, os primeiros encontros em grupo se destinaram a estudos e discussões de textos e artigos sugeridos pela mediadora ${ }^{5}$, os quais abordavam metodologias e estratégias de ensino, e, também, proporcionavam discussões sobre a importância do ensino por investigação e para a promoção da alfabetização científica, com a intenção de contribuir para a formação inicial e continuada dos participantes e para a elaboração de suas sequências de aulas. Concomitante a esses momentos de estudos, discussões e reflexões, cada licenciando elaborou, ministrou e analisou uma sequência de aulas, baseada nos pressupostos que orientavam o PRO, ou seja, um ensino por investigação e que contribuísse para o desenvolvimento de habilidades relacionadas à $\mathrm{AC}$ em estudantes da educação básica.

Para este trabalho será apresentada a análise da sequência de aulas desenvolvida pela licencianda autora desta pesquisa. Com o auxílio das discussões e reflexões em grupo e orientação da mediadora, a licencianda reelaborou, por quatro vezes, sua sequência de aulas, relacionada a conceitos de soluções. O processo de elaboração teve duração de aproximadamente quatro meses. Assim, a cada nova proposta da sequência, um encontro entre mediadora e licencianda foi realizado, a fim de discutir e refletir sobre aspectos a serem reconsiderados nas aulas da sequência, para que esta pudesse contemplar as características norteadoras do PRO.

Após o processo de reelaboração da sequência, a licencianda desenvolveu as quatro aulas propostas para alunos da segunda série do ensino médio de uma escola da rede pública de ensino, de uma cidade do sul de Minas Gerais. A sequência de aulas contemplava conceitos de soluções, com o objetivo de desenvolver os principais conteúdos relacionados à temática “Água de Consumo”. Um breve relato de cada aula ministrada está descrito no Quadro 1.

Quadro 1. Detalhamento das aulas ministradas

\begin{tabular}{|c|l|}
\hline Aula & \multicolumn{1}{|c|}{ Detalhamento da aula } \\
\hline Aula 1 & $\begin{array}{l}\text { Levantamento das concepções prévias dos alunos por meio da questão problema: } \\
\text { "Sobre a água que bebemos, se adicionarmos a ela certa quantidade de sólido, é possível } \\
\text { prever qual o máximo desse sólido irá dissolver?” Em seguida pediu-se que os alunos } \\
\text { elaborassem um desenho sobre solução. }\end{array}$ \\
\hline Aula 2 & $\begin{array}{l}\text { Experimento: preparo de solução de sulfato de cobre. Mediado e dicutido pela } \\
\text { licencianda por meio de questionamentos aos alunos. }\end{array}$ \\
\hline Aula 3 & $\begin{array}{l}\text { Leitura e interpretação de rótulos: conceitos de concentração. Elaboração de um novo } \\
\text { desenho sobre soluções pelos alunos. }\end{array}$ \\
\hline Aula 4 & $\begin{array}{l}\text { Debate sobre os desenhos elaborados pelos alunos e realização de exercícios sobre } \\
\text { cálculo de concentração. }\end{array}$ \\
\hline
\end{tabular}

Fonte: elaborado pelas autoras.

\footnotetext{
${ }^{5}$ Os textos eram sugeridos, previamente, pela mediadora, para posteriores discussões e reflexões nos encontros em grupo. Todos os licenciandos compareciam aos encontros com uma leitura prévia dos artigos.
} 
Para o desenvolvimento da sequência de aulas, foram contempladas quatro aulas, com duração de 50 minutos cada.

\section{Metodologia de análise}

As aulas ministradas pela licencianda foram gravadas em vídeo, para posterior transcrição e análise dos dados. Após a realização das aulas, licencianda e mediadora analisaram as transcrições de cada aula primeiro individualmente, e depois juntas, a fim de confrontar e discutir os resultados obtidos. Assim, todas as análises aqui apresentadas foram realizadas por meio de um processo de reflexão orientada, entre licencianda e mediadora, utilizando de referenciais teóricos para sua compreensão, de forma a contribuir para a formação mais reflexiva da licencianda sobre sua prática. Ainda, para evidenciar a reflexão, trechos extraídos das transcrições dos encontros reflexivos entre mediadora e licencianda serão evidenciados, assim como excertos de seu diário de campo.

Para a análise, considerou-se a abordagem investigativa alcançada em cada aula, bem como o nível cognitivo das questões propostas pela licencianda, além do nível de alfabetização científica que as aulas puderam promover. Essas três perspectivas para análise foram contempladas, pois acredita-se que um ensino com características de investigação pode contribuir significativamente para o desenvolvimento de habilidades inerentes ao processo de alfabetização científica (BYBEE, 1997; SASSERON; CARVALHO, 2008).

Os Niveis Investigativos utilizados para a análise dos elementos pedagógicos presentes na sequência de aulas foram baseados no trabalho de Silva $(2011)^{6}$, e estão dispostos no Quadro 2, seguidos da descrição das características que cada nível engloba, em uma ordem crescente de abordagem investigativa (N1 a N4).

Quadro 2. Nível investigativo para análise das aulas da unidade didática ministrada

\begin{tabular}{|l|l|l|l|l|}
\hline \multicolumn{1}{|c|}{ Critérios } & \multicolumn{1}{|c|}{$\mathbf{N 1}$} & \multicolumn{1}{c|}{$\mathbf{N 2}$} & \multicolumn{1}{|c|}{$\mathbf{N 3}$} \\
\hline $\begin{array}{l}\text { Não apresenta } \\
\text { características } \\
\text { investigativas }\end{array}$ & $\begin{array}{c}\text { Tangencia } \\
\text { características } \\
\text { investigativas }\end{array}$ & $\begin{array}{l}\text { Apresenta algumas } \\
\text { características } \\
\text { investigativas }\end{array}$ & $\begin{array}{c}\text { Atividade } \\
\text { investigativa }\end{array}$ \\
\hline $\begin{array}{l}\text { Levantamento } \\
\text { das concepções } \\
\text { dos alunos (ou } \\
\text { retomada das } \\
\text { ideias) }\end{array}$ & Não apresenta. & $\begin{array}{l}\text { A partir de } \\
\text { questões que } \\
\text { parecem abordar } \\
\text { pouco o que os } \\
\text { alunos já sabem. }\end{array}$ & $\begin{array}{l}\text { A partir de questões } \\
\text { contextualizadas em } \\
\text { relação ao assunto } \\
\text { e ao cotidiano do } \\
\text { aluno. }\end{array}$ & $\begin{array}{l}\text { Pertinente } \\
\text { ao assunto, } \\
\text { contextualizado } \\
\text { com a realidade do } \\
\text { aluno. }\end{array}$ \\
\hline
\end{tabular}

continua

\footnotetext{
${ }^{6}$ Este trabalho propõe vários elementos pedagógicos considerados essenciais em atividades por investigação. No entanto, nesta pesquisa, serão analisados apenas alguns deles.
} 
Quadro 2. continuação

\begin{tabular}{|c|c|c|c|c|}
\hline Critérios & N1 & $\mathbf{N} 2$ & N3 & $\mathbf{N} 4$ \\
\hline $\begin{array}{l}\text { Questão } \\
\text { problema }\end{array}$ & Não apresenta. & $\begin{array}{l}\text { Apresentação de } \\
\text { perguntas sobre } \\
\text { o conteúdo, } \\
\text { que podem ser } \\
\text { respondidas } \\
\text { consultando o } \\
\text { livro didático, por } \\
\text { exemplo. }\end{array}$ & $\begin{array}{l}\text { Apresenta questões } \\
\text { para serem } \\
\text { investigadas e estão } \\
\text { relacionadas ao } \\
\text { tema. }\end{array}$ & $\begin{array}{l}\text { Um problema } \\
\text { bem delineado, } \\
\text { cujas respostas } \\
\text { poderão ser } \\
\text { alcançadas } \\
\text { por meio da } \\
\text { realização de uma } \\
\text { atividade, busca } \\
\text { de informações e } \\
\text { discussão. }\end{array}$ \\
\hline Laboratório & $\begin{array}{l}\text { Verificação ou } \\
\text { ilustração de } \\
\text { conceitos. }\end{array}$ & $\begin{array}{l}\text { Com } \\
\text { características } \\
\text { de verificação, } \\
\text { porém com } \\
\text { uma exploração } \\
\text { conceitual inicial. }\end{array}$ & $\begin{array}{l}\text { Características } \\
\text { de atividade } \\
\text { experimental } \\
\text { investigativa ainda } \\
\text { não bem explorada } \\
\text { pelo professor, } \\
\text { seja pelo excesso } \\
\text { de conceitos ou } \\
\text { por não delimitar } \\
\text { as questões } \\
\text { exploradas. }\end{array}$ & $\begin{array}{l}\text { Explora a } \\
\text { atividade } \\
\text { experimental } \\
\text { de forma } \\
\text { investigativa. }\end{array}$ \\
\hline $\begin{array}{l}\text { Questões } \\
\text { durante as } \\
\text { aulas }\end{array}$ & $\begin{array}{l}\text { Não exploram } \\
\text { conceitualmente } \\
\text { os dados obtidos } \\
\text { na atividade e } \\
\text { nas aulas. }\end{array}$ & $\begin{array}{l}\text { Exploram } \\
\text { parcialmente os } \\
\text { dados obtidos, } \\
\text { sem solicitação de } \\
\text { conclusões. }\end{array}$ & $\begin{array}{l}\text { Exploram os } \\
\text { dados obtidos, } \\
\text { com solicitação de } \\
\text { conclusões. }\end{array}$ & $\begin{array}{l}\text { Exploram os } \\
\text { dados obtidos, } \\
\text { com solicitação } \\
\text { de conclusões e } \\
\text { aplicação a novas } \\
\text { situações. }\end{array}$ \\
\hline $\begin{array}{l}\text { Sistematização } \\
\text { das aulas }\end{array}$ & Não apresenta. & $\begin{array}{l}\text { Sem } \\
\text { encaminhamento } \\
\text { de questões } \\
\text { para análise e de } \\
\text { exploração de } \\
\text { hipóteses. }\end{array}$ & $\begin{array}{l}\text { A partir dos } \\
\text { resultados das } \\
\text { análises propostas } \\
\text { e exploração de } \\
\text { hipóteses. }\end{array}$ & $\begin{array}{l}\text { A partir das } \\
\text { análises dos } \\
\text { resultados, do } \\
\text { confronto das } \\
\text { ideias iniciais } \\
\text { e finais, da } \\
\text { exploração de } \\
\text { hipóteses e } \\
\text { das respostas } \\
\text { ao problema } \\
\text { proposto. }\end{array}$ \\
\hline
\end{tabular}

Fonte: elaborado pelas autoras.

Os níveis cognitivos das questões propostas pelo professor também são de suma importância, pois parecem estar relacionados ao nível cognitivo das respostas dos alunos, que se apresentam de maior grau cognitivo em aulas que assumem características investigativas (SUART; MARCONDES, 2009). 
As questôes propostas pela licencianda foram analisadas segundo a categorização de Suart e Marcondes (2009), adaptadas por estas autoras a partir dos critérios propostos por Shepardson e Pizzini (1991). Os níveis para esta categorização estão dispostos no Quadro 3.

Quadro 3. Nível cognitivo das questões propostas pela licencianda

\begin{tabular}{|l|l|}
\hline Nível & \multicolumn{1}{|c|}{ Descrição } \\
\hline P1 & Solicita que o estudante relembre uma informação a partir de dados adquiridos. \\
\hline P2 & $\begin{array}{l}\text { Solicita que o estudante desenvolva atividades como sequenciar, confrontar, contrastar, } \\
\text { empregar leis e conceitos para solucionar um problema. }\end{array}$ \\
\hline P3 & $\begin{array}{l}\text { Solicita ao estudante que utilize as informações adquiridas para propor hipóteses, realizar } \\
\text { deduções, analisar situações e generalizar. }\end{array}$ \\
\hline
\end{tabular}

Fonte: elaborado pelas autoras.

A Alfabetização Cientifica (AC) foi analisada a partir dos critérios sugeridos por Bybee (1997), que podem ser utilizados para investigar os níveis possíveis de serem alcançados durante as aulas desenvolvidas. Os níveis propostos podem ser descritos, no Quadro 4, como:

Quadro 4. Critérios para análise dos níveis de Alfabetização Científica propostos por Bybee (1997)

\begin{tabular}{|l|l|}
\hline \multicolumn{1}{|c|}{ Critérios } & \multicolumn{1}{c|}{ Descrição } \\
\hline $\begin{array}{l}\text { Sem Alfabetização } \\
\text { Científica }\end{array}$ & $\begin{array}{l}\text { Os estudantes não fazem relações ou não conseguem responder } \\
\text { questões relacionadas às abordagens científicas. Não manifestam em seu } \\
\text { diálogo ou escrita conceitos, contextos ou capacidades cognitivas para } \\
\text { identificar ou resolver as questões propostas. }\end{array}$ \\
\hline $\begin{array}{l}\text { Alfabetização } \\
\text { Científica Nominal }\end{array}$ & $\begin{array}{l}\text { Os estudantes identificam o conceito científico, mas apresentam um } \\
\text { entendimento que sugere concepções alternativas ou equivocadas. }\end{array}$ \\
\hline $\begin{array}{l}\text { Alfabetização } \\
\text { Científica Funcional }\end{array}$ & $\begin{array}{l}\text { Os estudantes relatam um conceito corretamente, porém possuem } \\
\text { um entendimento restrito sobre ele, o que pode ser apenas uma } \\
\text { memorização. }\end{array}$ \\
\hline $\begin{array}{l}\text { Alfabetização } \\
\text { Científica Conceitual }\end{array}$ & $\begin{array}{l}\text { Os estudantes constroem uma compreensão sobre conceitos científicos } \\
\text { essenciais, relacionando-os e apresentam conhecimentos sobre } \\
\text { procedimentos e sobre o processo de investigação das ciências e } \\
\text { tecnologias. }\end{array}$ \\
\hline $\begin{array}{l}\text { Alfabetização } \\
\text { Científica } \\
\text { Multidimensional }\end{array}$ & $\begin{array}{l}\text { Os estudantes apresentam entendimento além de conceitos científicos } \\
\text { específicos e dos processos de investigação das ciências. Eles } \\
\text { consideram características históricas, tecnológicas e sociais. }\end{array}$ \\
\hline
\end{tabular}

Fonte: elaborado pelas autoras.

As análises puderam, então, contribuir para investigar como a licencianda desenvolveu cada uma de suas aulas, de acordo com suas características e o contexto envolvido, utilizando as categorias de análise. Ainda, possibilitou investigar se o PRO contribuiu para a formação inicial da professora ao auxiliá-la na análise e reflexão de sua própria prática. 
Regência e análise de uma sequência de aulas de química: ...

\section{Resultados e Discussão}

\section{Nível Investigativo alcançado nas aulas desenvolvidas}

O Quadro 5 mostra que o levantamento das concepções dos alunos para a aula 1 foi classificado no nível N4, uma vez que, nessa aula, foram levantadas as concepções prévias dos estudantes por meio de questões relacionadas ao assunto e ao contexto proposto na sequência. Esse elemento foi classificado nas aulas 2 e 3 no nível N3, ou seja, o levantamento das ideias foi feito por meio de questões contextualizadas quanto ao assunto e cotidiano dos alunos. Já a aula 4 foi classificada em N2, pois o levantamento das ideias foi feito por meio de questões que abordavam pouco o conhecimento dos alunos, pois as questões estavam relacionadas aos desenhos elaborados pelos alunos, o que limitou as discussões durante essa aula.

Quadro 5. Classificação de elementos presentes nas aulas e seus respectivos níveis investigativos

\begin{tabular}{|l|c|c|c|c|}
\hline \multicolumn{1}{|c|}{ Elementos } & Aula 1 & Aula 2 & Aula 3 & Aula 4 \\
\hline Levantamento das concepções dos alunos & N4 & N3 & N3 & N2 \\
\hline Problematização & N3 & N3 & N1 & N1 \\
\hline Laboratório & - & N3 & - & - \\
\hline Questões para os alunos & N1 & N3 & N2/N3 & N2 \\
\hline Sistematização & N1 & N3 & N2 & N2 \\
\hline
\end{tabular}

Fonte: elaborado pelas autoras.

A importância das ideias prévias está em relacionar os conteúdos estudados sobre ciências ao contexto em que o aluno está inserido, atribuindo assim, um caráter mais real para melhor compreensão dos conceitos pelos estudantes, de modo que eles também possam observar a utilidade em estudar tais conceitos das ciências (ZULIANI; ÂNGELO, 1999).

Pode-se considerar a diferença nos níveis investigativos das aulas para esse elemento pedagógico, devido, talvez, às diferentes abordagens realizadas, bem como ao objetivo de cada uma delas. A diferença das abordagens realizadas em sala de aula pela licencianda pode ser evidenciada através de dois trechos, das aulas 1 e 4, respectivamente.

Exemplo aula 1:

14 - L: [...] vocês acham que existem solucõoes no nosso dia a dia?

15 - Alunos: Sim

16 - L: Me dê um exemplo de solução no nosso dia a dia

17 - A4: Café

$18-\mathrm{A} 5-$ Suco

19 - L: Por que vocês acham que café e suco são soluções? O café é uma solução?

Exemplo aula 4:

10 - L: Como que você desenhou? 


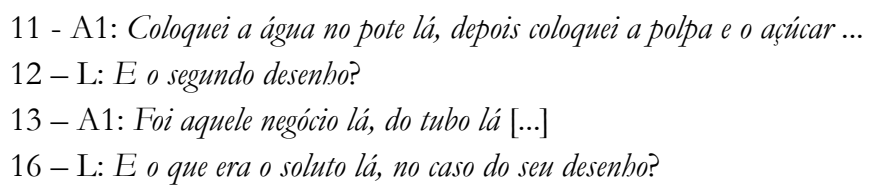

Ou seja, as primeiras aulas possibilitaram um nível mais alto de investigação devido as questões levantadas estarem relacionadas aos conceitos e ao cotidiano dos estudantes. Já as abordagens realizadas na aula 4 ficaram restritas somente a explicações, pelos alunos, de seus desenhos elaborados, não sendo feitas relações com o primeiro desenho proposto por eles ou com as aulas anteriores, embora essa ação tenha sido proposta pela licencianda em seu plano. No entanto, ainda é importante salientar que, nessa última aula, a professora em formação inicial pretendia realizar uma sistematização das ideias, e seu interesse estava em possibilitar que os estudantes elaborassem suas próprias conclusões.

A problematização para as aulas 1 e 2 foi classificada no nível N3, ou seja, a licencianda propôs a questão problema que assumia características investigativas e que estava relacionada ao tema da sequência. A questão abordada pela licencianda nas aulas 1 e 2 foi "Até quando um sólido é solúvel em água?". Pode-se observar que esta questão está relacionada ao contexto e apresenta uma investigação para que os alunos proponham hipóteses e possíveis soluções. As aulas 3 e 4 foram classificadas, quanto ao elemento problematização, no nível N1, pois a licencianda não apresenta a questão problema ou alguma problematização.

O trecho da transcrição entre mediadora e licencianda durante o encontro individual reflexivo evidencia o exposto:

M: Problematização... nas duas primeiras aulas a gente está colocando N3... querfazer alguma mudança?

L: Não [...] Acho que en fiquei meio perdida de colocar essa questão problema... eu comecei a desenvolver essas aulas e acabei esquecendo...na três e na quarta foi o desenho... fiquei meio que perdida onde colocar a questão problema.

A licencianda e a mediadora refletem sobre os aspectos que poderiam ter ocasionado tal esquecimento. Assim, durante as aulas 3 e 4, devido a apreensão em conceituar as aulas e a ansiedade em dar sequência a abordagem proposta, a licencianda acabou não problematizando as aulas. A licencianda reflete, ainda, juntamente com a mediadora, que a ausência da questão problema pode ter contribuído para que os alunos tenham desenvolvido um entendimento limitado sobre os conceitos abordados, fato que pode ser compreendido por meio das classificações para os níveis de alfabetização científica, apresentados mais adiante.

É importante ressaltar que um ensino voltado para a resolução de um problema, que esteja centrado na investigação e no questionamento, pode contribuir para o desenvolvimento cognitivo e para a alfabetização científica dos estudantes. A resolução de um problema pelos alunos pode auxiliar na construção de seus conhecimentos, uma vez que eles podem propor hipóteses e conclusões para solucioná-lo (BYBEE, 1997; SUART; MARCONDES, 2009).

\footnotetext{
${ }^{7}$ Experimento: preparação de soluções de diferentes concentrações de sulfato de cobre.
} 
Regência e análise de uma sequência de aulas de química: ...

O experimento realizado pela licencianda, na aula 2, ocorreu por meio de questões norteadoras e de uma questão problema. As questões levantadas pela licencianda nortearam os alunos a pensarem e construírem seus conhecimentos sobre o que poderia ser considerado uma solução, e quais os seus constituintes. A licencianda realizou intervenções e questionamentos a fim de que os alunos pudessem construir seus conhecimentos, o que contribuiu para que eles compreendessem, elaborando hipóteses e possíveis soluções, a quantidade de sólido que iria dissolver em determinado volume de solvente. O elemento pedagógico laboratório foi então classificado no nível N3, pois apresenta algumas características investigativas, tais como, levantamento de hipóteses, coleta de dados, análise de condições e elaboração de conclusões.

A licencianda, em suas reflexões com a mediadora, observou que o desenvolvimento do experimento ${ }^{7}$ foi o momento em que ela constatou situações importantes referentes a motivação e a curiosidade dos alunos. Ela destaca o interesse dos alunos pelos aparatos utilizados, bem como, a atenção desprendida por eles ao que iria ocorrer durante e depois do preparo da solução. No entanto, a licencianda também explicita dificuldades em realizar o experimento e controlar, concomitantemente, a agitação dos estudantes, os questionamentos propostos por eles e a sua mediação dialógica em sala de aula, conforme mostra o trecho do encontro individual reflexivo:

\footnotetext{
M: Em relação ao experimento... olhando as aulas...você acha que foi um experimento investigativo?

L: Eu acho que foi um experimento que eu percebi que eu perguntava e eles demoravam para participar, ai eu perguntava de novo... às vezes eles não respondiam o que eu queria...da metade do experimento para frente que eles começaram a participar mais [...] M: A que você atribui eles não quererem participar muito no inicio?

L: Acho que no inicio eles estavam mais... curiosos com o experimento, aí depois à medida que fui fazendo o experimento [...] eles foram participando porque foi dando para visualizar, a partir do terceiro tubinho [...] ai eles perceberam que a massa era maior que era o dobro... a cor está bem mais forte [...] Eles já queriam saber o que vai acontecer com o último... vai acontecer alguma coisa diferente vai sobrar?

M: Querem a resposta.

L: É.
}

O elemento pedagógico questões propostas para os alunos, na aula 1, foi classificado no nível N1, pois a licencianda não explora os conceitos e ideias obtidos durante a aula. No entanto, pode-se relacionar esse baixo nível (N1) associado à aula 1, devido ao foco da aula, que era o de levantar as ideias prévias dos alunos, e questões de menor nível investigativo eram necessárias para organizar as ideias dos estudantes. Já a aula 2 foi classificada como N3, talvez por se tratar de uma aula experimental, a qual pode ter contribuído para a proposição de questões que exploravam os dados obtidos e também requeriam que os alunos propusessem conclusões. Já as aulas 3 e 4, as quais foram destinadas, respectivamente, à elaboração dos desenhos e explicação desses pelos alunos, apresentam questões que foram classificadas como N2, ou seja, percebe-se que as inferências realizadas nestas aulas exploram parcialmente os dados obtidos, mas sem solicitar conclusões pelos estudantes. É importante salientar que, na aula 3, foi realizada uma atividade com rótulos de água mineral, mas a atividade ficou desvinculada das demais, pelo fato de a licencianda não conduzir a aula de maneira dialogada e investigativa, o 
que contribuiu para o baixo número de questões propostas, as quais eram, na sua maioria, de baixa exigência investigativa e cognitiva (Tabela 1).

A aula 1 foi classificada quanto a sistematização como N1, uma vez que essa aula não apresenta sistematização dos conceitos, pois foram propostas apenas questões iniciais para o levantamento das concepções prévias dos alunos a respeito de soluções. Já a aula 2 foi classificada no nível N3, ou seja, nessa aula ocorre a sistematização de algumas ideias, visto que a professora em formação inicial propõe questões que já direcionam os alunos para a resolução da questão problema, com auxílio dos resultados experimentais. A sistematização das aulas 3 e 4 foi classificada no nível investigativo N2, pois a licencianda concentrou as ideias das discussões em relação ao desenho que os alunos deveriam elaborar sobre soluções (aula 3) e a discussão dos desenhos propostos por eles (aula 4). Assim, pode-se observar que a licencianda não direciona essas duas últimas aulas para uma relação do primeiro com o segundo desenho proposto pelos alunos, e, também, não realiza intervenções para relacionar essas duas aulas com as demais, justificando a classificação no referido nível.

Ao analisar as aulas, a licencianda relata, em seu diário de campo, suas preocupações e anseios, argumentando sobre esses e outros fatores que poderiam ter interferido no desenvolvimento das aulas e nos dados e resultados obtidos. Ela relata que centrou sua atenção nos conceitos a serem abordados em suas aulas e ao seu planejamento, como pode-se observar em suas reflexões:

\begin{abstract}
Quando estava me preparando para as aulas, hoje percebo, que minha maior e principal preocupação era com o conteúdo e com o planejamento. Percebo que voltei minha atenção, ao preparar a aula, cuidando e me atentando para o conteúdo, e nos momentos de realização das aulas lembro que estava muito presa ao meu planejamento, tentando seguir à risca tudo o que foi planejado. Segui o planejamento como um roteiro, que não poderia ser alterado, acha que isso não foi tão legal.
\end{abstract}

Ela ainda relata em seu diário, que, durante a regência, se sentia ansiosa, o que parece ter refletido diretamente em suas aulas. Em alguns momentos das aulas, percebe-se que a licencianda assume uma postura de autoridade, quando sua fala predomina frente à dos alunos. A própria licencianda faz uma reflexão sobre o assunto:

Lembro que durante as aulas eu me sentia muito ansiosa, acho que por isso que em muitos momentos eu falava mais, explicava e dava respostas demais e não questionava os alunos, não os deixava falar. Acho que minha ansiedade não deixou que eu desenvolvesse minhas aulas como en queria, que os alunos participassem, falassem mais.

Bejarano e Carvalho (2003) assumem a ideia de que professores novatos, por terem vivenciado aspectos tradicionais de ensino, não adotam uma perspectiva investigativa tão facilmente, demonstrando dúvidas e inseguranças em como atuar de maneira a desenvolver uma atividade por investigação, interferindo, assim, em sua prática docente. 


\section{Nível cognitivo das questões propostas pela licencianda}

A Tabela 1 apresenta o nível cognitivo das questões propostas pela licencianda durante a sequência de aulas. O nível cognitivo das questões foi relacionado ao nível investigativo das aulas durante as discussões aqui apresentadas para auxiliar na compreensão de como a licencianda desenvolveu suas abordagens nas aulas.

Tabela 1. Classificação do nível cognitivo das questões propostas pela licencianda - Número de perguntas por categoria presente nas aulas

\begin{tabular}{lllll}
\hline & \multicolumn{4}{c}{ Quantificação do número de questões propostas por aulas } \\
\hline Nível Cognitivo & Aula 1 & Aula 2 & Aula 3 & Aula 4 \\
P1 & 13 & 8 & 13 & 6 \\
P2 & 8 & 3 & 7 & 0 \\
P3 & 9 & 10 & 0 & 0 \\
\hline
\end{tabular}

Fonte: elaborada pelas autoras.

Através da Tabela 1 pode-se observar que a maioria das questões propostas pela licencianda na aula 1 foram classificadas no nível $\mathrm{P} 1$, pois foram questões que exigiam que o aluno apenas recordasse uma informação a partir dos dados obtidos. Pode-se justificar a baixa exigência cognitiva das questões devido ao tipo de abordagem realizada nessa aula, uma vez que a licencianda propõe questionamentos relacionados ao cotidiano para levantar as ideias prévias dos alunos. Através de alguns trechos da aula pode-se evidenciar essas questões:

Turno 16 - L: Me dá um exemplo de solucão no nosso dia-a-dia. [P1]

Turno 48 - L: Então quando você vai preparar uma solução o que você tem que fazer mesmo?! [P1]

Turno 77 - L: O que tem no rótulo ((rótulo de água mineral)) que você já leu? [P1]

Mediadora e licencianda refletem sobre os níveis cognitivos propostos na primeira aula:

M: Aqui na aula 1... você começa explicando e começa a questionar... então você coloca algumas questões... o nivel de questão que você fazé P1...P1 é quando só recorda uma informação... você acha que está de acordo com a sua aula? Com esse nível de questão P1... a primeira aula? [...]

L: Eu queria que eles recordassem de alguma coisa que soubessem, mas que relacionassem com o cotidiano... ai nos momentos que perguntava se eles conheciam alguma solução do cotidiano eles conseguiam relacionar, mas só com o que eles já visualizaram o que é uma solução, eles falavam café ou leite com café...

Apesar do elevado número de questões classificadas como P1 na aula 1, pode-se notar que também foram propostas questões P2 e P3. Questões classificadas como P2 exigem que 
os alunos confrontem e contrastem ideias para a resolução de uma atividade, empregando conceitos para solucionar um problema. Já questões do nível P3 exigem que o aluno, utilizando as informações fornecidas, elabore hipóteses, deduza e analise situações, fazendo generalizações, aplicando o conhecimento em outros contextos.

Assim, pode-se exemplificar um questionamento da licencianda classificado no nível cognitivo P2: "A água que a gente bebe, que vocês acham que ela é? Uma mistura? Uma substância pura?”. Em outra questão proposta pela licencianda, ao levantar proposições sobre a composição da água, muitos alunos responderam que na água estão presentes sais minerais, e a licencianda os questionam da seguinte maneira, “e esses sais minerais são importantes para o nosso organismo?”, questão que foi classificada como P3, pois exige que o aluno proponha hipóteses e explicações em um contexto diferente do abordado, mas relacionado ao seu cotidiano.

A aula 2 apresenta um grande número de questões classificadas como P3, as quais solicitam que os estudantes utilizem as informações obtidas para elaborar hipóteses, avaliar condições, realizar inferências e generalizações. Pode-se relacionar a classificação do nível de exigência das questões propostas pela licencianda com o nível investigativo da aula, o qual apresenta elementos pedagógicos que transitam nos níveis N3 e N4. Assim, pode-se assumir que essa aula apresenta características investigativas, e que, por se tratar de uma aula experimental, permitiu que fossem propostas questões de nível cognitivo mais elevado, uma vez que os alunos participaram do experimento ao propor hipóteses para solucionar o problema proposto inicialmente.

Segundo Suart e Marcondes (2009), aulas investigativas podem contribuir para o desenvolvimento de questões de alta ordem cognitiva, o que, consequentemente, auxilia no desenvolvimento de habilidades cognitivas pelos estudantes.

As aulas 3 e 4 apresentam um grande número de questões classificadas no nível cognitivo P1. Pode-se relacionar essa classificação ao nível investigativo, N2, ou seja, essas aulas apresentam poucas características investigativas, visto que a licencianda concentrou as inferências e o debate realizados nessas duas aulas em discussões sobre a elaboração e explicação dos desenhos pelos alunos, não fazendo relações entre os desenhos, ou com o experimento ou as demais aulas.

A licencianda também relata em seu diário de campo, que, ao rever seus planejamentos, considera que poderia ter realizado intervenções mais significativas em sala de aula, conforme o seguinte trecho de sua reflexão:

\footnotetext{
Acredito que poderia ter mudado minhas intervençöes, hoje penso que deveria ter feito as perguntas de maneira que os alunos compreendessem melhor o que estava sendo questionado. Estava muito nervosa e ansiosa nas minhas aulas, eu queria cumprir com o que planejei e durante as aulas não consegui melhorar minhas intervençöes, de organizar as ideias. Estava muito ansiosa e insegura.
}

\section{Alfabetização científica alcançada nas aulas}

Quanto ao Nível de Alfabetização Científica (AC), a aula 1 está relacionada ao nível de AC funcional, onde os alunos apresentam os conceitos corretamente, porém exibem uma compreensão limitada sobre ele.

A aula 2 está relacionada ao nível de AC conceitual, uma vez que os alunos desenvolvem um entendimento sobre ciências, relacionando-os com seus entendimentos gerais das ciências. 
Regência e análise de uma sequência de aulas de química: ...

Pode-se também observar que os alunos compreendem aspectos sobre técnicas e procedimentos das ciências, que ocorreram durante a realização do experimento. As aulas 3 e 4 podem ser classificadas como AC funcional, em que os alunos apresentam um conceito corretamente, porém é uma compreensão restrita sobre ele, o que pode demonstrar que ocorreu apenas uma memorização dos conceitos estudados.

De tal modo, pode-se inferir, a partir das análises, que as aulas realizadas do modo investigativo contribuíram para o desenvolvimento de habilidades relacionadas a alfabetização científica. Ou seja, as aulas 1 e 2, apresentaram níveis investigativos mais elevados, e pode-se dizer que essas aulas se aproximam da AC funcional e conceitual, respectivamente. Já as aulas 3 e 4, que apresentaram níveis mais baixos de investigação, se aproximaram de uma AC funcional. Desta maneira, pode-se inferir que a abordagem investigativa contribui significativamente para a promoção da alfabetização científica, uma vez que contempla situações em que o aluno pode resolver um problema, propor hipóteses, analisar condições e propor uma solução para tal, o que auxilia no seu desenvolvimento cognitivo e conceitual.

Portanto, pode-se também salientar que o envolvimento no PRO contribuiu para a formação dessa licencianda, uma vez que ela percebeu a importância da reflexão de sua prática antes, durante e após o desenvolvimento das aulas. Ela também percebeu que é necessário atentar-se para a formação dos alunos, tendo o cuidado de, ao mediar as aulas, considerar as diversas vozes em sala, questionando os estudantes e levando-os a construírem suas concepções a respeito de determinado assunto.

\section{Considerações finais}

As análises das aulas ministradas pela licencianda mostram que ela propôs e desenvolveu uma sequência de aulas considerando um ensino por investigação e para a promoção da alfabetização científica, refletindo sobre a sua prática docente com o auxílio da mediadora. É importante destacar, ainda, que foram utilizados referenciais teóricos e categorias para que as reflexões pudessem estar embasadas em conhecimentos empíricos e vivenciados por outros professores, a fim de que a reflexão não se limitasse ao senso comum. A licencianda reconheceu, durante o PRO, que em alguns momentos de suas aulas se demonstrou ansiosa e insegura, sentimentos comuns devido à sua pouca experiência e familiaridade com o cenário de sala de aula e com as estratégias norteadoras do PRO. Tais aspectos influenciaram, principalmente, em sua postura e no desenvolvimento de suas aulas, uma vez que, em alguns momentos, a licencianda assume uma postura de autoridade, buscando cumprir com o que foi proposto para cada aula.

Pode-se observar, também, que a participação da licencianda no grupo de reflexão orientada parece ter contribuído para sua formação inicial, uma vez que, após suas experiências e reflexões, ela considera importante rever e repensar suas concepções e ações. Assim, vale ressaltar a importância da formação inicial docente voltada para a reflexão, uma vez que essa perspectiva pode contribuir para a formação do futuro professor, de forma que desenvolva a habilidade de refletir criticamente sobre suas propostas e prática didática.

Destaca-se ainda, que embora as ações propostas nesta pesquisa tenham ocorrido em momentos extraclasse, ou seja, não foram desenvolvidas nas disciplinas regulares da matriz curricular, e, ainda, tenham demandado um elevado tempo e dedicação por parte dos licenciandos 
e mediadora, considera-se que o PRO pode ser desenvolvido durante o curso de licenciatura, de forma que suas ações transitem entre as disciplinas de prática pedagógica e estágio supervisionado, visto que os benefícios evidenciados nesta pesquisa mostram a relevância e efetividade da estratégia formativa.

\section{Referências}

ABELL, S. K.; BRYAN, L. A. Reconceptualizing the elementary science methods course using a reflection orientation. Journal of Science Teacher Education, Dordrecht, v. 8, n. 3, p. 153-166, 1997.

ALARCÃO, I. Professores reflexivos em uma escola reflexiva. 8. ed. São Paulo: Cortez, 2011.

ALVES, F. E.; LIMA, V. A.; MARCONDES, M. E. R. O ensino experimental como ferramenta metodológica em um processo de formação continuada na perspectiva da reflexão orientada. In: ENCONTRO NACIONAL DE ENSINO DE QUÍMICA, 16., 2012, Salvador. Anais... Salvador: ENEQ, 2012. p. 1-12. Disponível em: <http://www.eneq2012. qui.ufba.br/modulos/submissao/Upload/43237.pdf >. Acesso em: 12 dez. 2016.

BEJARANO, N. R. R.; CARVALHO, A. M. P. Professor de ciências novato, suas crenças e conflitos. Investigações em Ensino de Ciências, Porto Alegre, v. 8, n. 3, p. 257-280, 2003. Disponível em: < http://www.if.ufrgs.br/ienci/artigos/Artigo_ID107/v8_n3_a2003.pdf>. Acesso em: 12 dez. 2016.

BIANCHINI, T. B. O ensino por investigação abrindo espaços para a argumentação de alunos e professores do ensino médio. 2011. 144 f. Dissertação (Mestrado) Faculdade de Ciências, Universidade Estadual Paulista, Bauru, 2011.

BYBEE, R. W. Achieving scientific literacy: from purposes to practices. Portsmouth: Heineman, 1997.

CACHAPUZ, A. et al. A necessária renovação do ensino de ciências. 2. ed. São Paulo: Cortez, 2005.

CARVALHO, A. M. P. Las prácticas experimentales en el proceso de enculturación cientifica. In: QUINTANILLA GATICA, M.; ADÚRIZ-BRAVO, A. (Ed.). Enseñar ciências en el nuevo milenio: retos e propuestas. Santiago: Universidade Católica de Chile, 2006. p. 73-90.

CHASSOT, A. Alfabetização científica: questões e desafios para a educação. 3. ed. Ijuí: Unijuí, 2003.

COPELLO LEVY, M. I.; SANMARTÍ PUIG, N. Fundamentos de un modelo de formación permanente del profesorado de ciencias centrado en la reflexión dialógica sobre las concepciones y las prácticas. Enseñanza de las Ciencias, Barcelona, v. 19, n. 2, p. 269-283, 2001. Disponível em: < https://ddd.uab.cat/record/1530>. Acesso em: 12 dez. 2016. 
Regência e análise de uma sequência de aulas de química: ...

FREITAS, D.; VILLANI, A. Formação de professores de ciências: um desafio sem limites. Investigação em Ensino de Ciências, Porto Alegre, v. 7, n. 3, p. 215-230, set. 2002. Disponível em: <http://www.if.ufrgs.br/ienci/artigos/Artigo_ID90/v7_n3_a2002.pdf>. Acesso em: 12 dez. 2016.

GATTI, B. A. Questão docente: formação, profissionalização, carreira e decisão política. In: CUNHA, C.; SOUSA, J. V.; SILVA, M. A. (Org.). Políticas públicas de educação na América Latina: lições aprendidas e desafios. Campinas: Autores Associados, 2011. p. 303324.

KASSEBOEHMER, A. C.; FERREIRA, L. H. O espaço da prática de ensino e do estágio curricular nos cursos de formação de professores de química das IES públicas paulistas. Química Nova, São Paulo, v. 31, n. 3, p. 694-699, 2008. Disponível em: < http://dx.doi. org/10.1590/S0100-40422008000300038>. Acesso em: 12 dez. 2016.

MALDANER, O. A. A formação inicial e continuada de professores de química: professores/pesquisadores. Ijuí: Unijuí, 2000.

MELLADO JIMÉNEZ, V. Concepciones y prácticas de aula de profesores de ciências em formacion inicial de primaria y secundaria. Enseñanza de Las Ciencias, Barcelona, v. 14, n. 3, p. 289-302, 1996. Disponível em: < http://www.raco.cat/index.php/ensenanza/article/ viewFile/21460/93425>. Acesso em: 12 dez. 2016.

MORTIMER, E. F. As chamas e os cristais revisitados: estabelecendo diálogos entre a linguagem científica e a linguagem cotidiana no ensino das ciências da natureza. In: SANTOS, W. L. P. S.; MALDANER, O. A. (Org.). Ensino de química em foco. Ijuí: Unijuí, 2010. p. 180-207.

PREDEBON, F.; PINO, J. C. Uma análise evolutiva de modelos didáticos associados às concepções didáticas de futuros professores de química envolvidos em um processo de intervenção formativa. Investigações em Ensino de Ciências, Porto Alegre, v. 14, n. 2, p. 237-254, 2009. Disponível em: <http://www.if.ufrgs.br/ienci/artigos/Artigo_ID216/ v14_n2_a2009.pdf>. Acesso em: 12 dez. 2016.

SASSERON, L. H.; CARVALHO, A. M. P. Almejando a alfabetização científica no ensino fundamental: a proposição e a procura de indicadores do processo. Investigações em Ensino de Ciências, Porto Alegre, v. 13, n. 3, p.333-352, 2008. Disponível em: <http:// www.if.ufrgs.br/ienci/artigos/Artigo_ID199/v13_n3_a2008.pdf>. Acesso em: 12 dez. 2016.

SHEPARDSON, D. P.; PIZZINI, E. L. Questioning levels of junior high school science textbook and their implications for learning textual information. Science Education, Hoboken, v. 75, n. 6, p. 673-688, 1991. Disponível em: <http://dx.doi.org/10.1002/ sce.3730750607>. Acesso em: 12 dez. 2016.

SILVA, C. S.; OLIVEIRA, L. A. A. Formação inicial de professores de química: formação específica e pedagógica. In: NARDI, R. (Org.). Ensino de ciências e matemática, I: temas sobre a formação de professores. São Paulo: Editora Unesp, 2009. Disponível em: <http:// dx.doi.org/10.7476/9788579830044 >. Acesso em: 11 fev. 2016. 
SILVA, D. P. Questões propostas no planejamento de atividades experimentais de natureza investigativa no ensino de química: reflexões de um grupo de professores. 2011. 212 f. Dissertação (Mestrado em Ensino de Ciências) - Faculdades de Educação, Universidade de São Paulo, São Paulo, 2011.

SILVA, M. H. S.; DUARTE, M. C. A relação entre discurso e prática pedagógica na formação inicial de professores. Investigações em Ensino de Ciências, Porto Alegre, v. 7, n. 3, p. 231-243, 2002. Disponível em: < http://www.if.ufrgs.br/ienci/artigos/Artigo_ID91/v7_n3_ a2002.pdf>. Acesso em: 12 dez. 2016.

SILVA, R. M. G.; SCHNETZLER, R. P. Concepções e ações de formadores de professores de Química sobre o estágio supervisionado: propostas brasileiras e portuguesas. Química Nova, São Paulo, v. 31, n. 8, p. 2174-2183, 2008. Disponível em: < http://dx.doi. org/10.1590/S0100-40422008000800045>. Acesso em: 12 dez. 2016.

SUART, R. C.; MARCONDES, M. E. R. A manifestação de habilidades cognitivas em atividades experimentais investigativas no ensino médio de química. Ciências \& Cognição, Rio de Janeiro v. 14, n. 1, p. 50-74, 2009. Disponível em: <http://pepsic.bvsalud.org/pdf/ cc/v14n1/v14n1a05.pdf>. Acesso em: 12 dez. 2016.

VILLANI, A.; FRANZONI, M.; VALADARES, J. M. Desenvolvimento de um grupo de licenciandos numa disciplina de prática de ensino de física e biologia. Investigações em Ensino de Ciências, Porto Alegre, v. 13, n. 2, p. 143-168, 2008.

ZULIANI, S. R. Q. A.; ÂNGELO, A. C. D. A utilização de estratégias metacognitivas por alunos de química experimental: uma avaliação da discussão de projetos e relatórios. In: ENCONTRO NACIONAL DE PESQUISA EM EDUCAÇÃO EM CIÊNCIAS, 2., 1999, São Paulo. Anais... São Paulo: ENPEC, 1999. Disponível em: <http://www.nutes.ufrj.br/ abrapec/iienpec/Dados/trabalhos/A51.pdf>. Acesso em: 12 dez. 2016.

Artigo recebido em 13/04/2016. Aceito em 13/06/2016. 